\title{
Gravity waves observed from the Equatorial Wave Studies (EWS) campaign during 1999 and 2000 and their role in the generation of stratospheric semiannual oscillations
}

\author{
V. Deepa ${ }^{1}$, G. Ramkumar ${ }^{1}$, and B. V. Krishna Murthy ${ }^{2}$ \\ ${ }^{1}$ Space Physics Laboratory, Vikram Sarabhai Space Centre, Trivandrum-695 022, India \\ ${ }^{2}$ B1 Ceebros, 47/20, IIIrd Main Road, Gandhi Nagar, Adayar, Chennai-600 020, India
}

Received: 23 February 2006 - Revised: 14 July 2006 - Accepted: 24 August 2006 - Published: 20 October 2006

\begin{abstract}
The altitude profiles of temperature fluctuations in the stratosphere and mesosphere observed with the Rayleigh Lidar at Gadanki $\left(13.5^{\circ} \mathrm{N}, 79.2^{\circ} \mathrm{E}\right)$ on 30 nights during January to March 1999 and 21 nights during February to April 2000 were analysed to bring out the temporal and vertical propagation characteristics of gravity wave perturbations. The gravity wave perturbations showed periodicities in the $0.5-3$-h range and attained large amplitudes $(4-5 \mathrm{~K})$ in the mesosphere. The phase propagation characteristics of gravity waves with different periods showed upward wave propagation with a vertical wavelength of 5-7 km. The mean flow acceleration computed from the divergence of momentum flux of gravity waves is compared with that calculated from monthly values of zonal wind obtained from RH-200 rockets flights. Thus, the contribution of gravity waves towards the generation of Stratospheric Semi Annual Oscillation (SSAO) is estimated.
\end{abstract}

Keywords. Meteorology and atmospheric dynamics (Middle atmosphere dynamics; Waves and tides)

\section{Introduction}

The importance of gravity waves in the middle atmospheric dynamics is now widely recognized and they are important in determining the gross circulation of much of the mesosphere through the process of momentum deposition at heights where wave saturations occurs. Thus, the upward propagating gravity waves generated at lower heights provide a significant coupling between different regions of the atmosphere. The momentum deposition by dissipating gravity waves is largely responsible for driving the Quasi Biennial Oscillation (QBO) (Lindzen and Holton 1968; Lindzen, 1981; Holton, 1983; Fritts, 1984; Dunkerton, 1997; Baldwin

Correspondence to: G. Ramkumar

(geetha_ramkumar@vssc.gov.in) et al., 2001) in the lower stratosphere and the Semiannual Oscillations (SAO) in the stratospheric (SSAO) and mesospheric (MSAO) regions (Holton and Wehrbein, 1980). Extensive studies on the source and propagation characteristics of gravity waves in the middle atmosphere have been carried out in the past several years using both observations and theoretical models (e.g. Hines, 1991; Tsuda et al., 1994; Vincent and Alexander, 2000). Most of the observations on the gravity wave characteristics were made in the middle and high latitudes (e.g. Marsh et al., 1991; Mitchell et al., 1991; Wilson et al., 1991a, b; Whiteway and Carswell, 1994, 1995; McDonald et al., 1998). Over the tropical region, observations using the high-resolution radiosonde data have shown a strong correlation between the strength of convection in the troposphere and the level of wave activity in the upper stratosphere (Vincent and Alexander, 2000).

The eastward phase of SAO was supposed to be driven by fast Kelvin waves (Holton, 1975). But later studies showed that their forcing was insufficient to drive the SAO (Hitchman and Leovy, 1988). The gravity wave forcing is believed to be important in driving stratospheric QBO and SAO (Dunkerton, 1982, 1997; Sato and Dunkerton, 1997; Ray et al., 1998; Scaife et al., 2002). The relative contribution of various scales of waves to the forcing of the SAO is yet to be quantified. Since the QBO and SAO are the dominant features of middle atmospheric dynamics, their representation is an important requirement in the climate models. Even though some of the Global Circulation Models (GCM) could simulate SAO, the simulated SAOs differ significantly among GCMs and are often not realistic (Amodei et al., 2001). There are number of theoretical studies on the wave-mean flow interaction and the generation of QBO and SAO (Dunkerton, 1982; Jackson and Gray, 1994; Alexander and Holton, 1997; Sassi and Garcia, 1997; Medvedev and Klaassen, 2001). The momentum fluxes of vertically propagating equatorial waves and gravity waves are important parameters in the simulation of QBO and SAO. From

Published by Copernicus GmbH on behalf of the European Geosciences Union. 
the divergence of momentum flux the meanflow acceleration produced by these waves can be estimated. There are observational studies which show that the contribution of equatorial waves alone is not sufficient to generate the observed meanflow acceleration (Sato and Dunkerton, 1997; Sasi and Deepa, 2001; Sasi et al., 2003).

To study the effects of gravity waves on the middle and upper atmosphere it is necessary to acquire the knowledge of the wave properties, such as phase speed, amplitude, wavelengths and gravity wave spectrum. A measure of momentum flux of gravity waves is to be specified for parameterizing gravity wave effects in GCMs. Measurements of wave perturbation cannot be directly converted to momentum flux without detailed knowledge of the properties associated with every wave perturbation. Currently, there is lack of observations at low-latitude stations about the gravity wave properties and their interaction with meanflow. Using Upper Atmospheric Research Satellite data and UK Met Office analysed wind data and temperature fields Alexander and Rosenlof (2003) estimated the gravity wave meanflow forcing in the stratosphere.

Two major experimental campaigns were conducted during January-March 1999 and February-April 2000 using the MST radar and the Rayleigh lidar at the tropical station Gadanki $\left(13.5^{\circ} \mathrm{N}, 79.2^{\circ} \mathrm{E}\right)$, mainly to determine the characteristics of equatorial waves (Krishnamurthy et al., 2002; Sasi et al., 2003). In the 1999 campaign, which was conducted for a period of 46 days from 18 January-5 March 1999, there were Rayleigh lidar temperature measurements from Gadanki. In the February-April 2000 campaign, conducted for a period of 34 days during 29 February to 2 April, along with temperature measurements using the Rayleigh $\mathrm{Li}$ dar from Gadanki, wind measurements using rocket flights were also carried out simultaneously from a nearby location Sriharikota Range (SHAR) $\left(13.7^{\circ} \mathrm{N}, 80.2^{\circ} \mathrm{E}\right)$. The scientific objectives of the Equatorial Wave Studies (EWS) 2000 campaign were (1) to delineate equatorial waves in winds and temperatures in the region from the troposphere to the mesosphere, and to estimate the vertical fluxes of their horizontal momentum and (2) to delineate gravity waves in temperatures in the stratosphere- mesosphere region and to evaluate the role of gravity waves in the evolution of SSAO.

As a continuation of this campaign, $\mathrm{RH} 200$ rocket flights were conducted from SHAR once in a month up to July 2000. These wind data in the middle atmospheric region were used to derive the monthly mean wind and thus the SAO and the mean flow acceleration. The present study is based on the temperature data of $\sim 3$-h duration, collected from lidar observations at NARL, Gadanki, during 30 nights of the 1999 EWS campaign and 21 nights of the EWS 2000 campaign.

In this paper the temporal and vertical propagation characteristics of shorter period gravity waves are studied. The potential energy and momentum fluxes of prominent periodic components of gravity waves are calculated. From the divergence of momentum flux of gravity waves their contri- bution towards the generation of SSAO are estimated. These estimated values are compared with observed meanflow acceleration using rocket-measured wind values.

\section{Data and method of analysis}

The lidar system at Gadanki uses the second harmonic output of the laser source at $532 \mathrm{~nm}$ with maximum energy of about $0.4 \mathrm{~J}$ per pulse. The laser is operated at a pulse width of $7 \mathrm{~ns}$ and a repetition rate of $20 \mathrm{~Hz}$. The Rayleigh receiver is used for collecting the backscattered light from air molecules and operates in the range of $\sim 30$ to $\sim 80 \mathrm{~km}$. It employs a vertical Newtonian type telescope with a field of view of $1 \mathrm{mrad}$ and the primary mirror is a concave mirror with effective diameter of $750 \mathrm{~mm}$. The lidar system records a 5000 laser shots averaged photon count profile as one frame with a time resolution of $250 \mathrm{~s}$. The photon count profiles thus obtained from the basic data are used for studies concerning atmospheric density and temperature. Estimation of temperature from lidar data and the sources of error are explained in detail by Parameswaran et al. (2000). In order to reduce the statistical error in the derived parameters, the raw data is integrated for 3 bins in altitude and time, so that the temperature profiles are obtained with an altitude resolution of $900 \mathrm{~m}$ and a time resolution of 12.5 -min. The statistical error due to signal variance is $\sim 1 \mathrm{~K}$ in the lower altitudes $(30-50 \mathrm{~km})$ and increases with altitude $(\sim 2.5 \mathrm{~K}$ at $65 \mathrm{~km})$. To minimize the uncertainty due to various errors, temperature data in the altitude region $27-60 \mathrm{~km}$ alone is used for the present study.

The zonal and meridional winds used in the present study are obtained from RH-200 rocket flights from SHAR. The altitude profiles of horizontal winds in the $20-65 \mathrm{~km}$ region with a vertical resolution of $1 \mathrm{~km}$ are obtained by tracking the chaff released from the RH-200 rockets.

The time series of temperature fluctuations $T^{\prime}(z)$ at each altitude is obtained by subtracting the mean temperature $T_{0}(z)$ from the observed temperatures $T(z)$ in the height region of $27-60 \mathrm{~km}$. The time series of temperature fluctuations during $\sim 3 \mathrm{~h}$ were initially subjected to spectral analysis by Maximum Entropy Method (MEM) to look for the presence of prominent periodicities and it was found that an $\sim 2.5$ $\mathrm{h}$ period is present on all days during the two campaign periods. The prominent periodicities of gravity waves were also identified by spectral analysis using Fast Fourier Transform (FFT), which could give the height profiles of amplitudes and phases corresponding to all days of the observation period. From the height profiles of amplitudes and phases, the vertical propagation characteristics were studied for all prominent harmonic periodicities. It may be noted here that as 14 data points go into the FFT analysis at each altitude, the standard error in the amplitude is reduced by $\sqrt{ } 14$. The available potential energy and momentum flux of prominent periodicities of gravity wave components were also calculated. From the divergence of momentum flux, the mean flow acceleration 
(a)

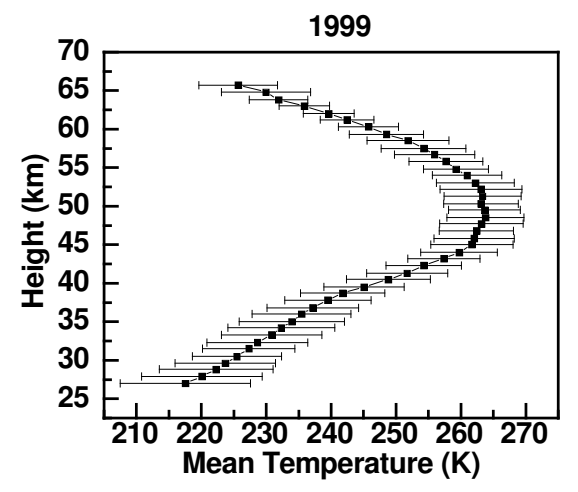

(c)

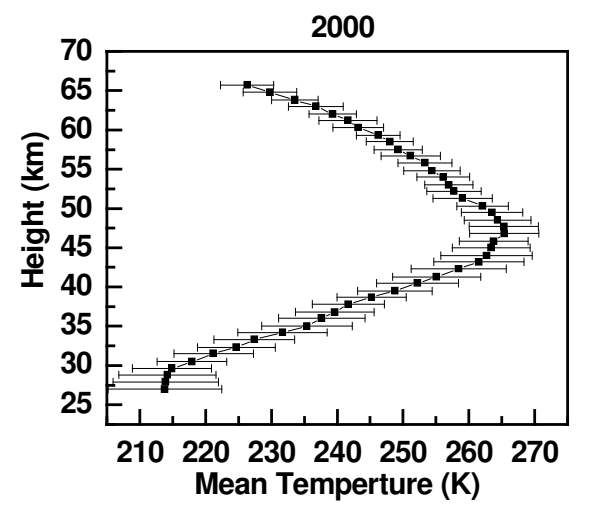

(e)

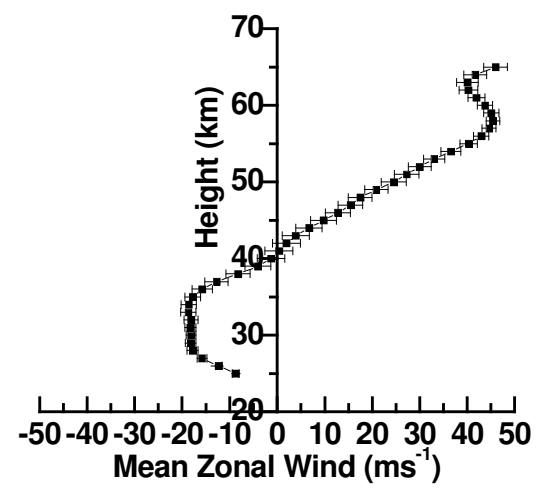

(b)

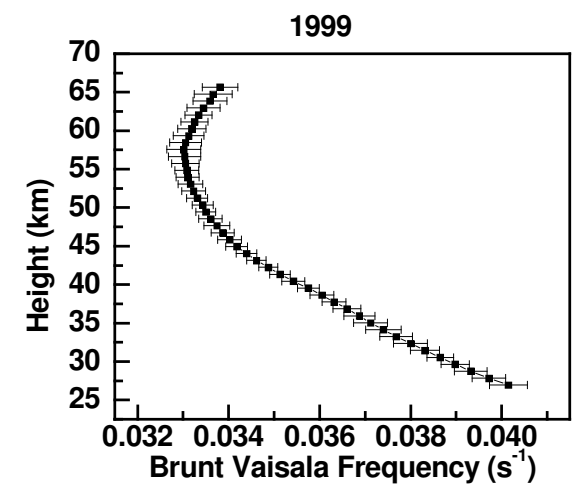

(d)

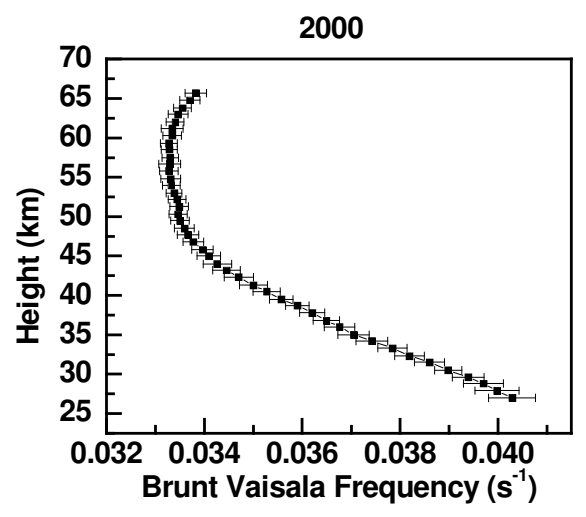

(f)

Fig. 1. Mean values of (a) temperature (1999), (b) Brunt Väisälä Frequency (1999), (c) temperature (2000), (d) Brunt Väisälä Frequency (2000), (e) Zonal Wind (2000), (f) Meridional Wind (2000).

in the $40-60 \mathrm{~km}$ height region were estimated. The mean flow acceleration is also calculated from monthly mean values of zonal winds obtained from $\mathrm{RH}-200$ rocket data and were compared with the derived values.

\section{Results and discussion}

\subsection{Vertical propagation characteristics}

The altitude profiles of the mean temperature $(T)$, the BruntVäisälä frequency $(N)$, the zonal wind $(u)$ and meridional wind $(v)$ for the whole period of observation during the 1999 and 2000 campaigns are shown in Figs. 1a-f. Mean 
(a)

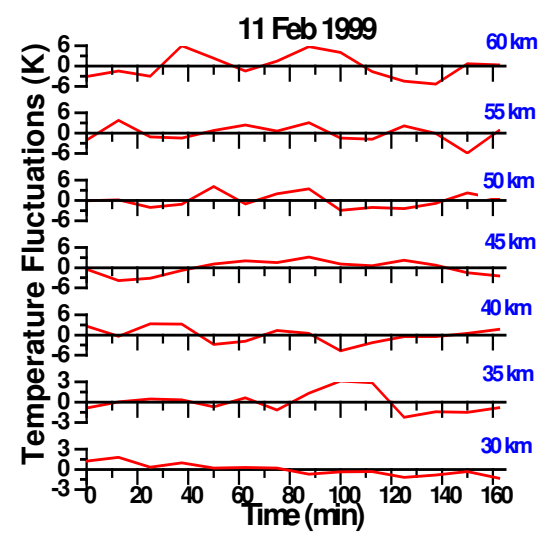

(b)

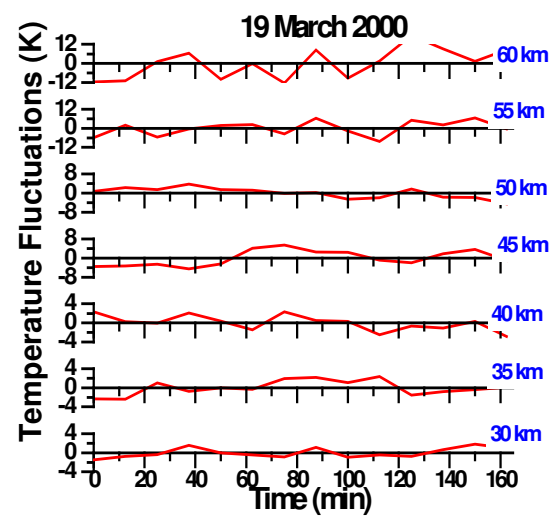

Fig. 2. Time series of temperature fluctuations at $30 \mathrm{~km}, 35 \mathrm{~km}, 40 \mathrm{~km}, 45 \mathrm{~km}, 50 \mathrm{~km}, 55 \mathrm{~km}, 60 \mathrm{~km}$ height levels for the $162-\mathrm{min}$ time period (a) 11 February 1999, (b) 19 March 2000.

(a)

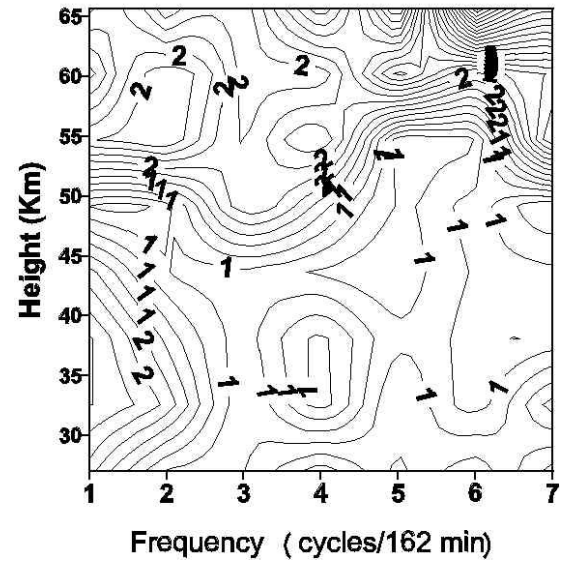

(b)

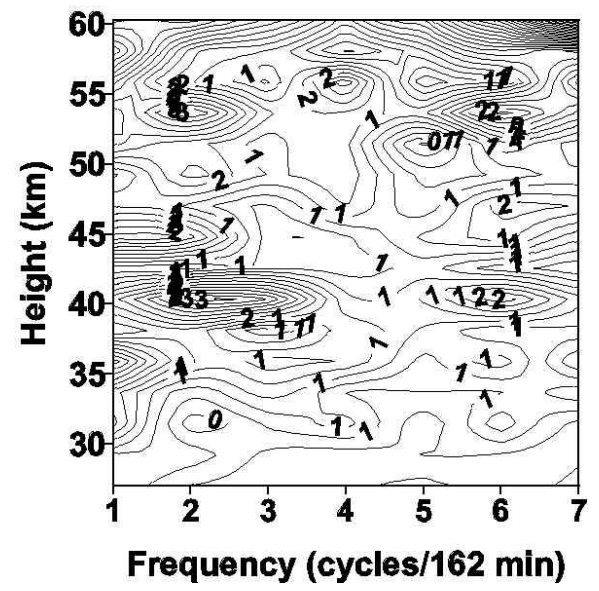

Fig. 3. Frequency-height section of spectral amplitudes of temperature fluctuations on (a) 11 February 1999 and (b) 19 March 2000.

temperature profiles show that the stratopause is warmer and sharper during 2000 compared to that during 1999. Corresponding variations are also seen in the "N profile". Mean zonal winds (available during 2000) are mostly westerly and meridional winds are very weak during the period of observation. Figures $2 \mathrm{a}$ and $\mathrm{b}$ give the time variation of temperature fluctuations at different height levels during 1999 and 2000 , respectively. The time variation of temperature fluctuation indicates that the wave motions of different periodicities with periods of few minutes to a few hours produce these perturbations. Figures $3 \mathrm{a}$ and $\mathrm{b}$ give the height distribution of spectral amplitudes of temperature fluctuations on 11 February 1999 and 19 March 2000, respectively. Although, there are day-to-day variations in the dominant periods present, on most of the days of observations, it is seen that a $162.5-\mathrm{min}$
( $\sim 2.5 \mathrm{~h}$ ) period is prominently present with large amplitudes and a clear downward phase propagation. Other periodicities such as 81-min, 54-min, 40-min, and 32-min are also present on some days.

The height profiles of the amplitudes and phases of all harmonic components derived from the Fourier analysis were studied in detail for deriving the propagation characteristics of these different periodicities of gravity waves (Figs. 4a and $b$ for the year 1999 and 2000, respectively). From the amplitude profile, it can be seen that the amplitude increases with height, indicating that there is growth of the gravity wave activity with height. This brings out one aspect of the gravity waves in the middle atmosphere, viz. the waves are generated somewhere down in the troposphere with small amplitudes and attain larger amplitudes as they propagate 
(a)

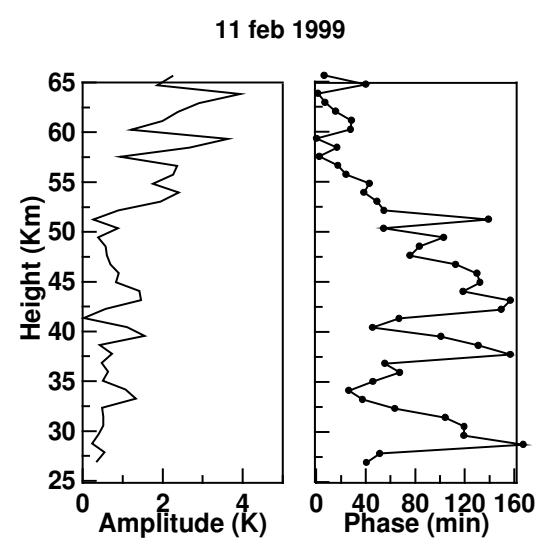

(b)

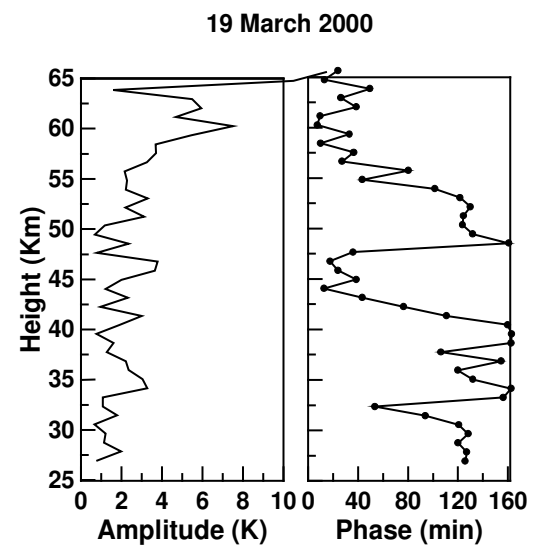

Fig. 4. Height profiles of amplitude and phase of 162-min period gravity wave during (a) 1999, (b) 2000 .

into the stratosphere and mesosphere. The maximum amplitude of the 162.5 -min period gravity wave is $4-5 \mathrm{~K}$ during 1999 and 6-8 K during 2000. The amplitude obtained for other periodicities, such as 81-min, 54-min, 40-min, and 32$\mathrm{min}$, are $2-3 \mathrm{~K}$. This indicates that $162.5-\mathrm{min}$ is the strongest component present throughout the observation period. An examination of the phase profiles clearly shows downward phase propagation, indicating upward energy propagation. Observed amplitudes, in general, are larger during 2000 compared to that during 1999.

The vertical wavelengths of different periods of gravity waves are inferred from the phase profiles on each day of observation during 1999 and 2000. The vertical wavelength of 162.5-min, 81-min, 54-min and 40-min are calculated from phase profiles in the stratosphere and mesosphere separately. The average vertical wavelength of all the observed periodicities in the stratosphere and mesosphere are given in Table $1 \mathrm{a}$ and b for 1999 and 2000, respectively. Vertical wavelengths are found to be slightly increased during 2000. For the 162.5 -min period, the vertical wavelength in the mesosphere is slightly larger than that in the stratosphere.

\subsection{Potential energy of gravity waves}

The gravity waves generated at the lower atmospheric region propagate upwards, carrying energy and momentum into stratospheric and mesospheric regions. Like the vertical propagation characteristics, the potential energy and momentum flux carried by the different periodicities of gravity waves also can be studied from the temperature fluctuations and the mean temperature. The available potential energy of prominent periodicities of gravity waves were calculated using the equation (Wilson et al., 1991a)

$$
E_{p}(z)=\frac{1}{2}\left(\frac{g(z)}{N(z)}\right)^{2}\left(\frac{T^{\prime}(z)}{T_{0}(z)}\right)^{2}
$$

Table 1. Average vertical wavelength of gravity waves for different periodicities both in stratosphere and mesosphere during (a) 1999 (b) 2000 .

\begin{tabular}{lcc}
\hline (a) & & \\
\hline $\begin{array}{c}\text { Period } \\
(\mathrm{min})\end{array}$ & Vertical Wavelength $(\mathrm{km})$ & \\
\cline { 2 - 3 } & & \\
& Stratosphere & Mesosphere \\
\hline 162.5 & 6.4 & 7.0 \\
81.2 & 6.2 & 7.1 \\
54.0 & 5.9 & 4.5 \\
40.0 & 5.2 & 5.5 \\
32.0 & 6.7 & 5.3 \\
\hline
\end{tabular}

\begin{tabular}{lcc}
\hline (b) & & \\
\hline $\begin{array}{c}\text { Period } \\
(\text { min) }\end{array}$ & Vertical Wavelength $(\mathrm{km})$ & \\
\cline { 2 - 3 } & Stratosphere & Mesosphere \\
\hline 162.5 & 7.1 & 7.5 \\
81.2 & 6.4 & 6.6 \\
54.0 & 8.3 & 6.0 \\
40.0 & 4.5 & 4.0 \\
32.0 & 6.5 & 5.2 \\
\hline
\end{tabular}

where $g(z)$ is the acceleration due to gravity, $N(z)$ is the Brunt-Väisälä frequency, $T^{\prime}(z)$ is the amplitude of the particular period, and $T_{0}(z)$ is the mean temperature. $N$ is calculated from the mean temperature profiles. Figures $5 \mathrm{a}-\mathrm{e}$ and 6a-e show the altitude profiles of the mean $E p$ for different periods during 18 January to 5 March 1999 and 29 February to 2 April 2000, respectively. The observed variation of 
(a)

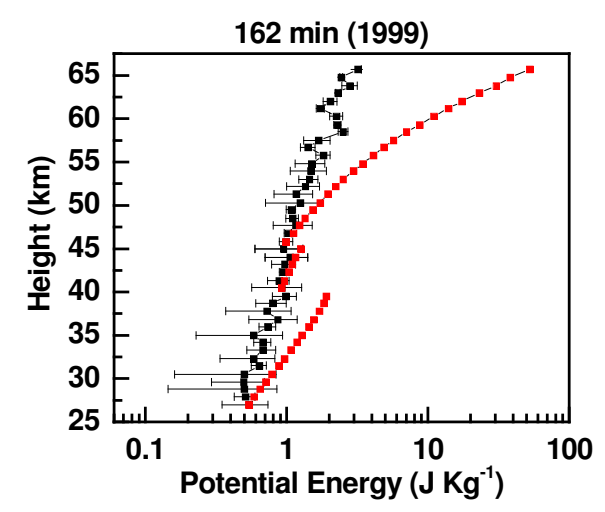

(c)

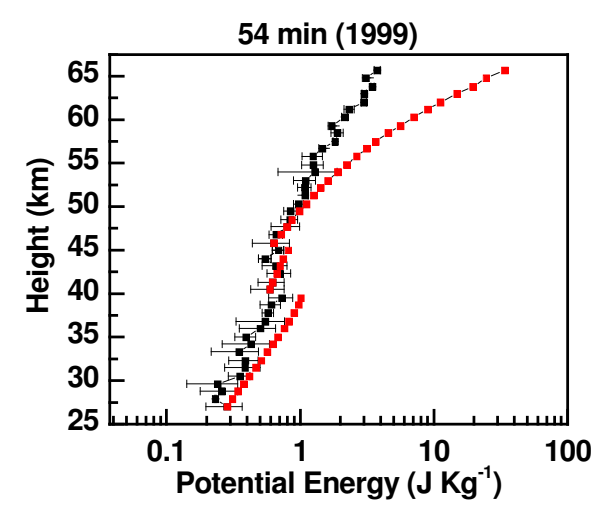

(e)

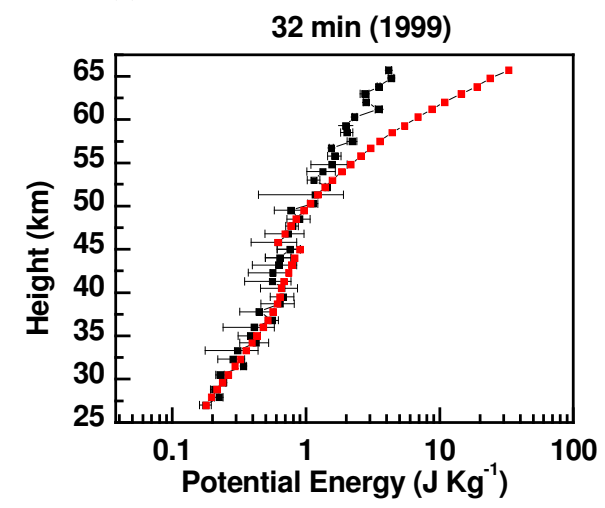

(b)

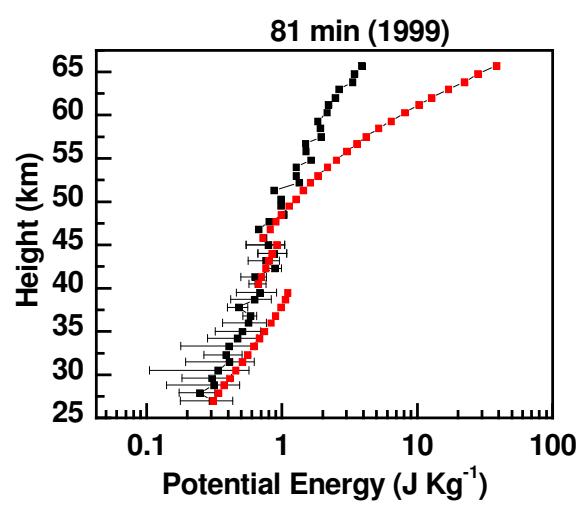

(d)

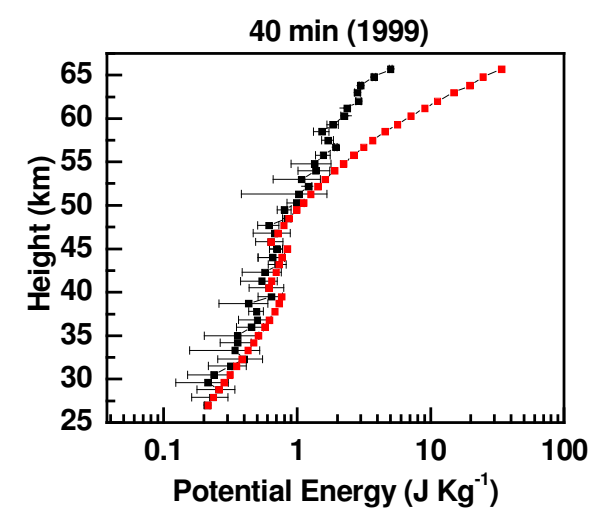

Fig. 5. Height profiles of potential energy for (a) 162-min, (b) 81-min, (c) 54-min, (d) 40-min, and (e) 32-min period gravity waves during 1999. Black squares represents the observed potential energy and red squares represent the theoretically expected potential energy.

potential energy (PE) with height is compared with the theoretically expected growth of PE. The theoretically expected growth of gravity waves is proportional to $\exp (z / H(z))$, where $H(z)$ is the scale height, $H(z)=k T(z) / m g, k$ is Boltzmann's constant, $T(z)$-temperature at the height $z \mathrm{~km}, m$ mean molecular weight, and $g$ the acceleration due to gravity. The black squares represent the observed potential en- ergy and red squares represent the theoretically expected potential energy. The PE of gravity waves during the year 1999 is slightly larger than that observed during the year 2000 .

Since the rate of growth is different in different height regions, wave growth is studied in three altitude regions separately, i.e. $27-40 \mathrm{~km}, 40-45 \mathrm{~km}$ and $45-65 \mathrm{~km}$. The observed growth of PE of gravity waves is smaller than the 
(a)

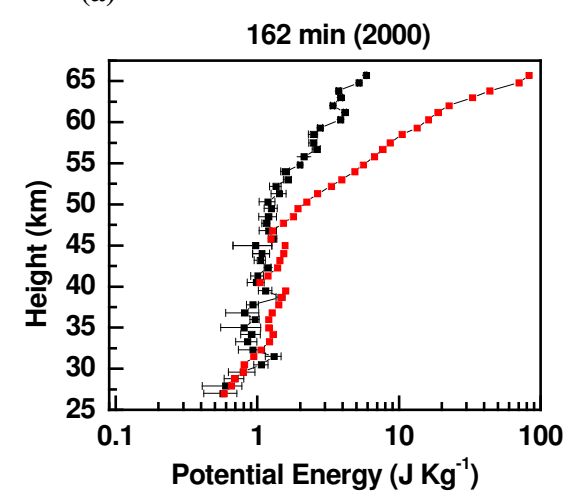

(c)

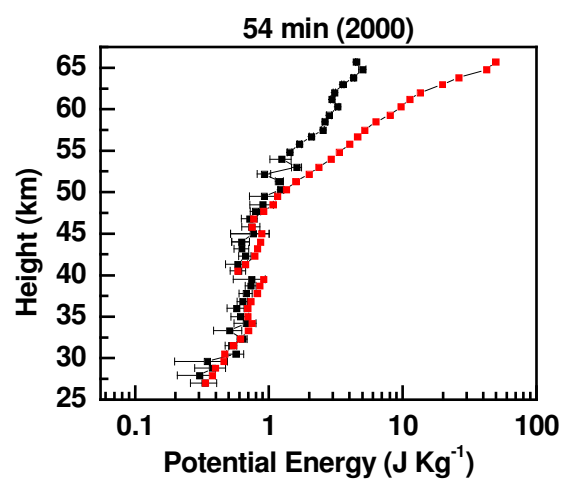

(e)

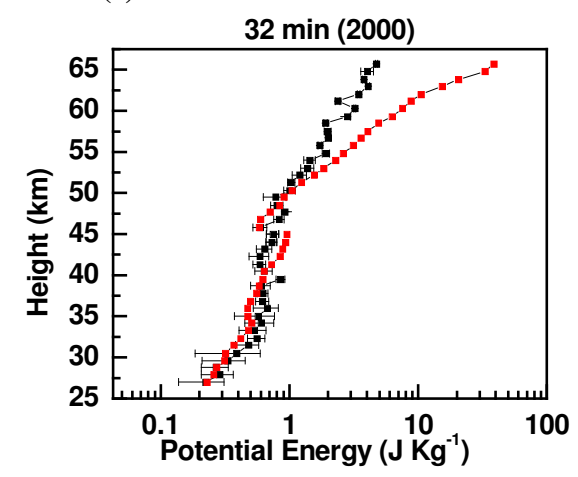

(b)

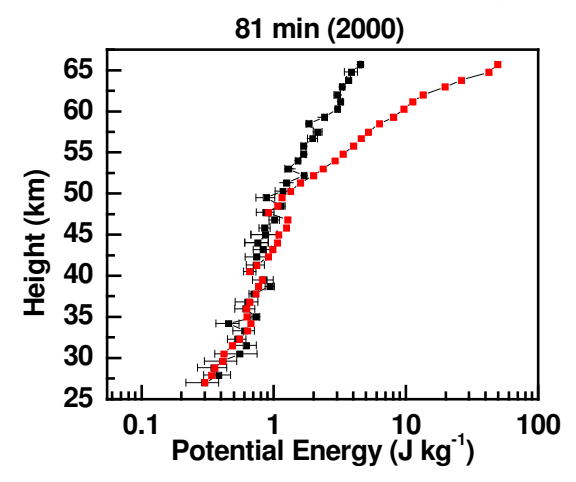

(d)

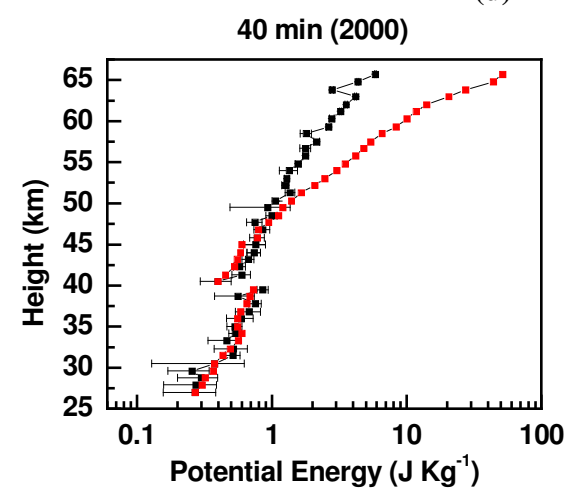

Fig. 6. Same as Fig. 5, but for the year 2000.

theoretically expected exponential growth, indicating the dissipation of wave energy as it goes up. During the year 2000 the wave growth in the stratosphere is almost matching the theoretically expected growth, except for 162-min.

The variation of potential energy with height is given by

$E_{\text {theory }}=E_{0} e^{\frac{z}{H_{0}}}$

$E_{\text {observed }}=E_{0} e^{\frac{z}{H_{1}}}$ where $E_{0}$ is the energy at height $z_{0}$, and $H_{0}$ is the scale height of the theoretically expected growth. In the case of dissipating waves, $E$ increases with scales $H_{1}>H_{0}$. Dissipation with height are derived as follows:

Dissipation $=\frac{\left|E_{\text {theory }}-E_{\text {observed }}\right|}{E_{\text {theory }}}=\frac{E_{0}\left[e^{\frac{z}{H_{0}}}-e^{\frac{z}{H_{1}}}\right]}{E_{0} e^{\frac{z}{H_{0}}}}$. 
Table 2. (a) Potential energy dissipated at various height levels (in percentage) during the year 1999. (b) Potential energy dissipated at various height levels (in percentage) during the year 2000.

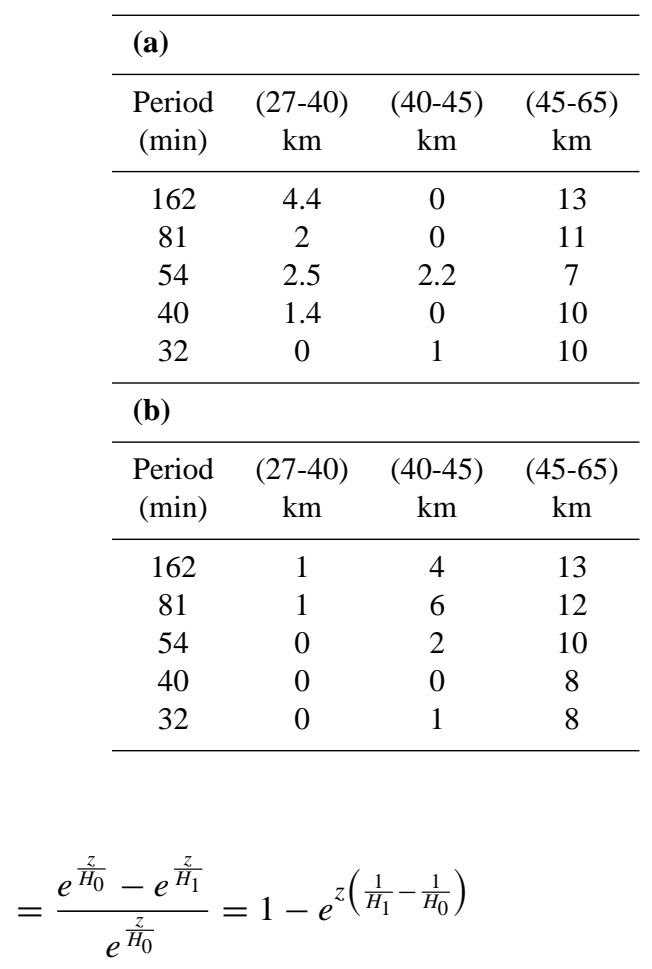

For $z=1 \mathrm{~km}$ intervals:

Dissipation $=1-e^{\left(\frac{1}{H_{1}}-\frac{1}{H_{0}}\right)}$.

The percentages of dissipated energy at various height levels for different periods are given in Table $2 \mathrm{a}$ and $\mathrm{b}$ for the years 1999 and 2000, respectively. Generally, for all the periods, the dissipation is found to be more or less the same in the lower mesospheric region for both years. In the stratosphere the 162-min, 81-min and 54-min periodicities show dissipation during 1999. During 2000 no dissipation is observed in the stratosphere. But in the $40-45 \mathrm{~km}$ altitude region dissipation is observed during 2000, but little or no dissipation is seen during 1999 . The gravity wave becomes more dissipated in the mesosphere (45-65 km height range) than in stratosphere during both years. The 162-min periodic component undergoes more dissipation than other periodicities.

\subsection{Momentum flux of gravity waves}

The contribution of gravity waves towards the generation of SSAO through wave-mean flow interaction is well understood (Dunkerton, 1982, 1997; Sato and Dunkerton, 1997; Ray et al., 1998; Scaife et al., 2002). In the present study, an attempt is made to calculate the momentum flux of gravity waves and in turn the divergence of the momentum flux, giving rise to mean flow acceleration. The vertical flux of zonal momentum per unit density for the prominent periodicities of gravity waves can be estimated using the parameters of the periodicities obtained in the present investigation. The flux $F$ is given by the equation

$$
F=\left\langle\overline{u^{\prime} w^{\prime}}\right\rangle=\frac{\omega}{N}\left(\frac{g}{\bar{N}}\right)^{2}\left\langle\frac{T^{\prime}}{\bar{T}}\right\rangle^{2},
$$

where $u^{\prime}$ and $w^{\prime}$ are wave perturbations in zonal and vertical winds. This equation is valid for $N \gg \omega \gg f$, where $N$ is the Brunt Väisälä frequency, $\omega$ is frequency of the wave and $f$ is the Coriolis parameter. $\bar{N}$ and $\bar{T}$ are the mean Brunt Väisälä frequency and temperature, respectively. $T^{\prime}$ is the temperature fluctuations for each period. The time series of $T^{\prime}$ for each period is reconstructed using respective amplitudes and phases. When weighted by the atmospheric density, $F$ yields the vertical flux of zonal momentum. The height profiles of the average momentum flux for different periods are shown in Figs. 7a and b for the years 1999 and 2000 , respectively. The values of $F$ lie between $0.05 \mathrm{~m}^{2} \mathrm{~s}^{-2}$ and $0.1 \mathrm{~m}^{2} \mathrm{~s}^{-2}$ below $45 \mathrm{~km}$ and above this altitude this value varies from $0.1 \mathrm{~m}^{2} \mathrm{~s}^{-2}$ to $0.2 \mathrm{~m}^{2} \mathrm{~s}^{-2}$. At the tropical station, Jicamarca $\left(12^{\circ} \mathrm{S}\right)$ the zonal momentum flux of gravity waves were reported to be in the range of $\sim 2-8 \mathrm{~m}^{2} \mathrm{~s}^{-2}$ (Hitchman et al., 1992) in the $70-85 \mathrm{~km}$ altitude region. The mean momentum fluxes in the lower stratosphere over the MU radar (at $35^{\circ} \mathrm{N}$ ) were $\sim 0.1-0.3 \mathrm{~m}^{2} \mathrm{~s}^{-2}$ (Fritts et al., 1990). Using MU radar Tsuda et al. (1990) obtained the momentum flux values of gravity waves for the periods $5 \mathrm{~min}$ to $2 \mathrm{~h}$ as $1.5 \mathrm{~m}^{2} \mathrm{~s}^{-2}$ in December-February, in the $60-90 \mathrm{~km}$ altitudes.

\subsection{Mean flow acceleration near the stratopause region}

In the previous sections, it is seen that the gravity waves originating from source regions propagate upwards, grow in amplitude and become dissipated at higher heights. These waves as they propagate interact with the background wind and produce mean flow acceleration, giving rise to SAO.

The mean flow acceleration is calculated using zonal wind (u) data collected from monthly flights of RH-200 rockets during February to July 2000. During 1999, the horizontal winds in the middle atmospheric region were not available, since rocket flights were not carried out during that campaign period. From the time series of $\boldsymbol{u}$, the mean zonal wind $(\overline{\boldsymbol{u}})$ was removed, in order to obtain zonal wind fluctuations. The time series of these zonal wind fluctuations were subjected to Fourier analysis, in order to obtain the amplitude and phase of SAO. The vertical profile of amplitude and phase of SAO is shown in Fig. 8. A maximum amplitude of $50 \mathrm{~ms}^{-1}$ is observed at $55 \mathrm{~km}$ and the phase is constant during second month, i.e. March. The mean flow acceleration is calculated as the difference in zonal wind speed between March and April. 
(a)

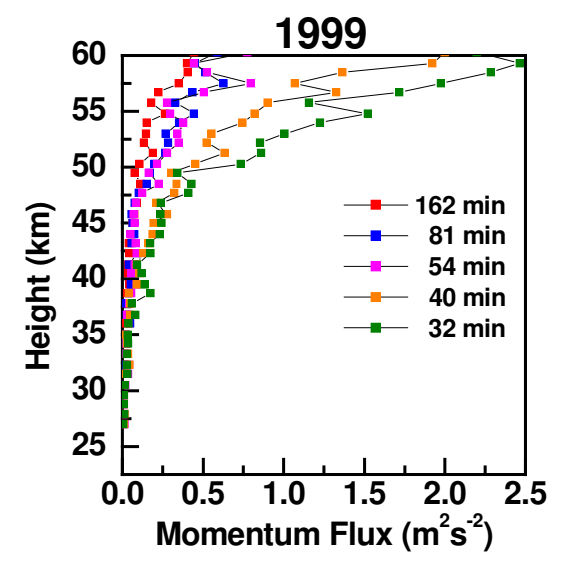

(b)

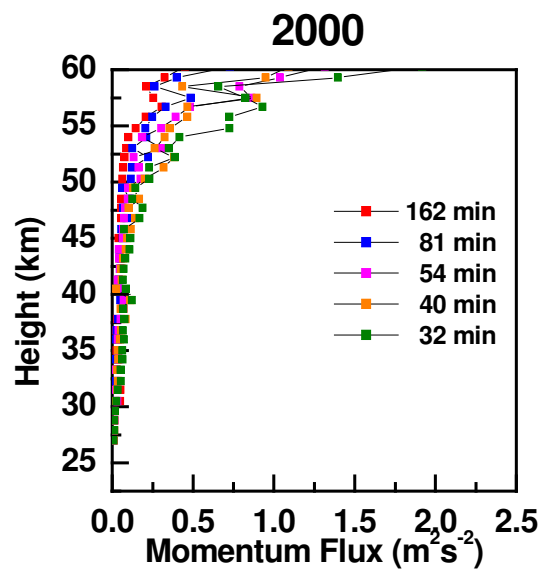

Fig. 7. Height profiles of momentum fluxes of 162-min, 81-min, 54-min, 40-min, and 32-min period gravity waves during (a) 1999 and (b) 2000.

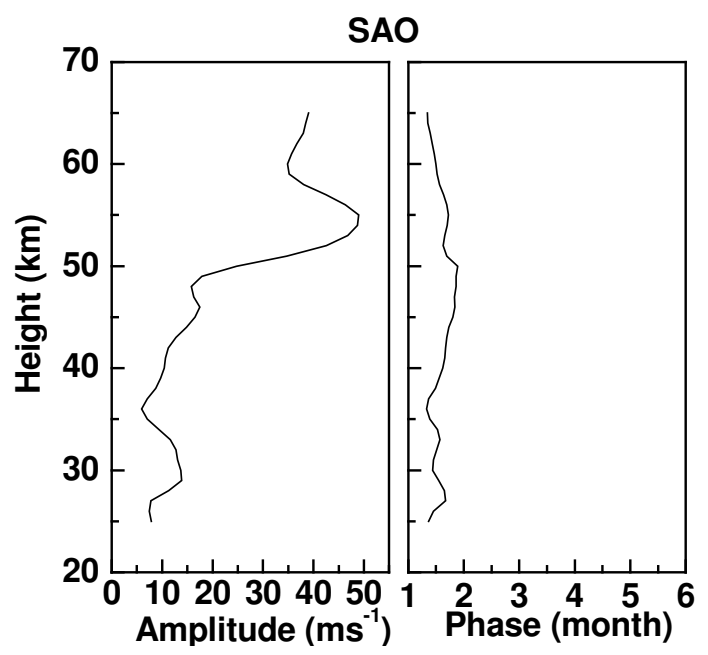

Fig. 8. Height profile of amplitude and phase of Semiannual Oscillation.

The mean flow acceleration produced by the gravity waves can be estimated using the equation (Lindzen, 1984)

$\frac{\partial u}{\partial t}=-\frac{d}{d z}\left\langle\overline{u^{\prime} w^{\prime}}\right\rangle+\frac{\left\langle\overline{u^{\prime} w^{\prime}}\right\rangle}{H}$

$H$ being the scale height. In the above equation, instead of $\overline{u^{\prime} w^{\prime}}$, we have used momentum flux derived from the temperature fluctuation using Eq. (5). To find out the contribution of gravity waves towards the generation of stratospheric $\mathrm{SAO}$, the divergence of momentum fluxes of gravity waves is estimated using Eq. (6). This equation treats the propagation and dissipation of a monochromatic wave. The total acceleration produced by the observed spectrum of waves is computed as the linear sum over all the waves in the spec-

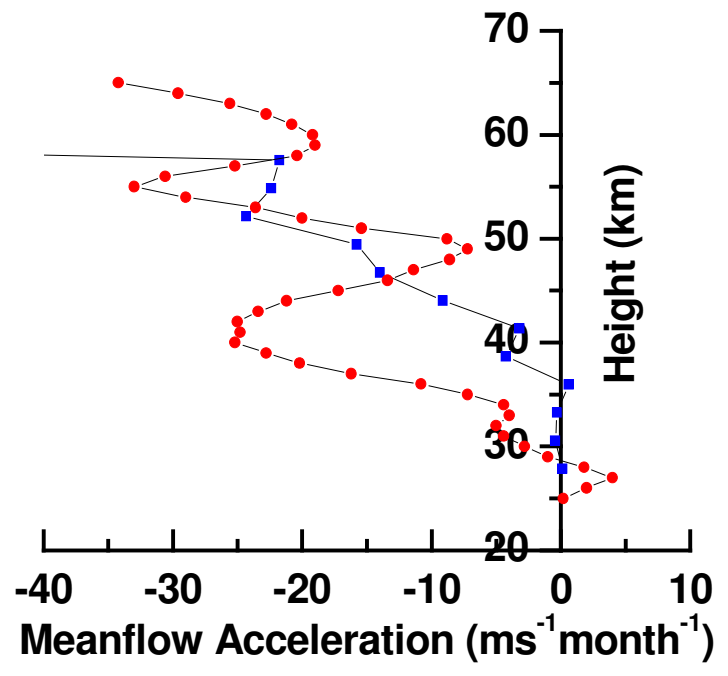

Fig. 9. Height profile of meanflow acceleration produced by gravity waves (blue squares) and observed meanflow acceleration obtained from rocket measured zonal winds (red circles).

trum. The maximum value of the estimated mean flow acceleration is $25 \mathrm{~ms}^{-1}$ month $^{-1}$, which is in good agreement with the earlier reported value of $1 \mathrm{~ms}^{-1}$ day $^{-1}$ (Fritts and Alexander, 2003; Horinouchi et al., 2003). Using MU radar wind observations Tsuda et al. (1990) obtained the meanflow acceleration produced by the divergence of momentum flux of $5 \mathrm{~min}-2 \mathrm{~h}$ gravity waves as $8-11 \mathrm{~ms}^{-1}$ day $^{-1}$ in the westward direction, in the $70-78 \mathrm{~km}$ altitude during winter.

The mean flow acceleration calculated using observed rocket wind data and that estimated from the momentum flux divergence of gravity waves are shown in Fig. 9. From the rocket measured wind data a maximum acceleration of 
$\sim 40 \mathrm{~ms}^{-1}$ month $^{-1}$ in the westward direction is observed at $55 \mathrm{~km}$. This is in agreement with earlier studies, that the first cycle of the stratospheric SAO begins with the stratopause easterly phase in northern winter (Garcia et al., 1997). The mean flow acceleration produced by gravity waves is estimated as $25 \mathrm{~ms}^{-1} \mathrm{month}^{-1}$ at $55 \mathrm{~km}$. Below $35 \mathrm{~km}$, there is negligible contribution from short period gravity waves towards the meanflow acceleration. From $35 \mathrm{~km}$ onwards the mean flow acceleration produced by gravity waves increases. The acceleration derived from gravity wave momentum flux divergence is less than the acceleration obtained from rocket wind data. In the $47-52 \mathrm{~km}$ height region the acceleration due to gravity wave is slightly overestimated. The difference between the observed acceleration and estimated acceleration may be attributed to long period gravity waves and planetary waves. Other possible sources for the generation of the easterly phase of SSAO are the equatorward propagation of wintertime Rossby waves and the advection of westward momentum by the mean meridional wind (Holton and Wehrbein, 1980; Ray et al., 1998). Fritts and Vincent (1987) presented the results of the analysis of gravity wave momentum fluxes in the mesosphere and lower thermosphere $(80$ $100 \mathrm{~km}$ ), inferred using a dual beam Doppler radar. They observed that $70 \%$ of the momentum flux and zonal wave drag was due to gravity waves with periods less than $1 \mathrm{~h}$, i.e. gravity waves of high frequency. But our study shows that zonal wind drag observed in the $30-60 \mathrm{~km}$ altitude region is mainly due to 2-3-h period gravity waves. This is because low frequency waves get dissipated more in the lower atmosphere than shorter period gravity waves and produce zonal drag. The high frequency waves travel to high altitudes without much dissipation in the lower altitude regions and becomes more dissipated at higher altitudes and produce zonal wind acceleration there.

Earlier studies using the data from these two (EWS 1999, EWS 2000) campaigns estimated the contributions of equatorial waves (fast and slow Kelvin waves) towards the generation of SAO as 25\% (Sasi et al., 2003). From this study it is seen that on average, about $50-60 \%$ of the mean flow acceleration is due to the divergence of momentum flux of gravity waves with periods in the range half an hour to three hours.

\section{Summary and conclusion}

The vertical and temporal characteristics of gravity waves in the $30-60 \mathrm{~km}$ altitude region during the January-March period of the two consecutive years (1999 and 2000) are studied using the Rayleigh lidar observations of temperature at Gadanki during the EWS campaign. The prominent periods of the gravity waves lie in the range of $30 \mathrm{~min}$ to $\sim 3 \mathrm{~h}$. The vertical wavelengths of these prominent periods are $\sim 5-7 \mathrm{~km}$. From the amplitude and phase profile, it is observed that the phase is decreasing with height indicating upward propagation of energy. The average poten- tial energy of prominent periods is less than $1 \mathrm{Jkg}^{-1}$ below the $45 \mathrm{~km}$ altitude and $1-3 \mathrm{Jkg}^{-1}$ in the $45-60 \mathrm{~km}$ altitude range. The potential energy increases almost exponentially with altitude below $45 \mathrm{~km}$ and above this the growth of the potential energy with altitude is less than the theoretically expected value. This gives the inference that the observed waves are more often damped in the mesosphere than in the stratosphere. The momentum flux values estimated for the prominent period of 162.5 -min are 0.05 to $0.1 \mathrm{~m}^{2} \mathrm{~s}^{-2}$ below $45 \mathrm{~km}$, and above this altitude this value varies from 0.1 to $0.2 \mathrm{~m}^{2} \mathrm{~s}^{-2}$. The westward mean flow acceleration produced by the divergence of momentum flux of gravity waves is $\sim 25 \mathrm{~ms}^{-1}$ month $^{-1}$. The observed meanflow acceleration is $40 \mathrm{~ms}^{-1}$ month $^{-1}$. The altitude profiles of the observed and estimated mean flow acceleration are in good agreement.

Acknowledgements. The authors wish to acknowledge the support provided by the colleagues at National Atmospheric Research Laboratory (NARL), S. V. University and MET facility, SHAR for conducting the campaigns during 1999 and 2000. V. Deepa wishes to express her gratitude towards Director, SPL and ISRO for providing the Research Associate position in Space Physics Laboratory.

Topical Editor U.-P. Hoppe thanks two referees for their help in evaluating this paper.

\section{References}

Alexander, M. J. and Holton, J. R.: A model study of zonal forcing in the equatorial stratosphere by convectively induced gravity waves, J. Atmos. Sci., 54, 408-419, 1997.

Alexander, M. J. and Rosenlof, K. H: Gravity wave forcing in the stratosphere: Observational constraints from the Upper Atmosphere Research Satellite and implications for parameterization in global models, 108, J. Geophys. Res., doi:10.1029/2003JD003373, 2003.

Amodei, M., Pawson, S., Scaife, A. A., Langematz, U., Lathoz, W., Li., D. M., and Simon, P.: The SAO and Kelvin waves in the EuroGRIPS GCMS and the UK Met. Office analyses, Ann. Geophys., 19, 99-114, 2001, http://www.ann-geophys.net/19/99/2001/.

Baldwin, M. P., Gray, L. J., Dunkerton, T. J., Hamilton, K., et al.: Quasi Biennial Oscillation, Rev. Geophys., 39, 179-229, 2001.

Dunkerton, T. J.: Theory of the mesopause semiannual oscillation, J. Atmos. Sci., 39, 2681-2690,1982.

Dunkerton, T. J.: The role of gravity waves in the quasi-biennial oscillation, J. Geophys. Res, 102, 26 053-26 076, 1997.

Fritts, D. C., : Gravity wave saturation in the middle atmosphere, A review of theory and observations, Rev. Geophys., 22, 275-308, 1984.

Fritts, D. C. and Vincent, R. A. : Mesospheric Momentum Flux Studies at Adelaide, Australia: Observations and a Gravity Wave-Tidal Interaction Model, J. Atmos. Sci., 44, 605-619, 1987.

Fritts, D. C., Tsuda, T., VanZandt, T. E., Smith, S. A., Sato, T., Fukao, S., and S. Kato.: Studies of velocity fluctuations in the lower atmosphere using the MU radar, II Momentum fluxes and energy densities, J. Atmos. Sci., 47, 51-66 1990. 
Fritts, D. C. and Alexander, M. J.: Gravity wave dynamics and effects in the middle atmosphere, 41(3), Rev. Geophys., doi:10.1029/2001RG000106, 2003.

Garcia, R. R., Dunkerton, T. J., Lieberman, R. S., and Vincent, R. A.: Climatology of the semiannual oscillation of the tropical middle atmosphere, J. Geophys. Res., 102, D22, 26019-26032, 1997.

Hines, C. O.: The saturation of gravity waves in the middle atmosphere, Part II: development of Doppler-spread theory, J. Atmos. Sci., 48, 1360-1379, 1991,

Hitchman, M. H. and Leovy, C. B.: Estimation of Kelvin wave contribution to the semiannual oscillation, J. Atmos. Sci., 45, 1462$1475,1988$.

Hitchman M. H., Bywaters, K. W., Fritts, D. C., Coy, L., Kudeki, E., and Suruchu, F.: Mean winds and momentum fluxes over Jicamarca, Peru, during June and August 1987, J. Atmos. Sci., 49, 2372-2383, 1992.

Holton, J. R.: The Dynamic Meteorology of the Stratosphere and Mesosphere, Meteor. Monogr., No 37, Amer. Meteor. Soc., $216 \mathrm{pp}, 1975$.

Holton J. R. and Wehrbein, W. M.: The role of planetary waves in the annual cycle of the zonal-mean circulation of the middle atmosphere, J. Atmos. Sci., 37, 1968-1983, 1980.

Holton, J. R.: The influence of gravity wave breaking on the general circulation of the middle atmosphere, J. Atmos. Sci., 40, $2497-$ $2507,1983$.

Horinouchi, T., Pawson, S., Shibata, K., Langematz, U., et al.: Tropical cumulus convection and upward propagating waves in middle-atmospheric GCMs, 60, J. Atmos. Sci., 2765-2782, 2003.

Jackson, D. R. and Gray, L. J.: Simulation of the semi-annual oscillation of the equatorial middle atmosphere using the extended u gamp general circulation model, Q. J. R. Meteorol. Soc., 120, 1559-1588, 1994.

Krishnamurthy, B. V., Satheesan, K., Parameswaran, K., Sasi, M. N., Geetha Ramkumar, et al.: Equatorial waves in temperature in the altitude range 4 to $70 \mathrm{~km}$, Q. J. R. Meteorol. Soc., 128, 819-838, 2002.

Lindzen, R. S. and Holton, J. R.: A study of the quasi-biennial oscillation, J. Atmos. Sci., 25, 1095-1107, 1968.

Lindzen, R. S.: Turbulence and stress owing to gravity wave and tidal breakdown, J. Geophys. Res., 86, 9707-9714, 1981.

Lindzen, R. S.: Gravity waves in the mesosphere, in: Dynamics of the middle atmosphere, edited by: Holton, J. R. and Matsuno, T., Terra. Publishing Company, Tokyo, 3-18, 1984.

Marsh, A. K. P., Mitchell, N. J., and Thomas, L.: Lidar studies of stratospheric gravity wave spectra, Planetary and Space Sci., 39, 1541-1548, 1991.

McDonald A. J., Thomas, L., and Wareing, D. P.: Night-to night changes in the characteristics of gravity waves at stratospheric and lower mesospheric heights, Ann. Geophys., 16, 229-237, 1998 ,

http://www.ann-geophys.net/16/229/1998/.
Medvedev, A. S. and Klaassen, G. P.: Realistic semiannual oscillation simulated in a middle atmosphere global circulation model, Geophys. Res. Lett., 28, 733-736, 2001.

Mitchell, N. J., Thomas, L., and Marsh, A. K. P.: Lidar observations of long period gravity waves in the stratosphere, Ann. Geophys. 9, 588-596, 1991, http://www.ann-geophys.net/9/588/1991/.

Parameswaran, K., Sasi, M. N., Ramkumar, G., Nair, P. R., Deepa, V., et al.: Altitude profiles of temperature from 4 to $80 \mathrm{~km}$ over the tropics from MST radar and lidar, J. Atmos. Sol. Terr. Phys., 62, 1327-1337, 2000.

Ray, E. A., Alexander, M. J., and Holton, J. R.: An analysis of the structure and forcing of the equatorial SAO in zonal wind, J. Geophys. Res., 103, 1759-1774, 1998.

Sasi, M. N. and Deepa, V.: Seasonal variation of equatorial wave momentum fluxes over Gadanki (13.5N, 79.2E), 19, 985-990, Annales Geophys., 2001.

Sasi, M. N., Krishnamurthy, B. V., Ramkumar, G., Satheesan, K.,: A study of equatorial wave characteristics using rockets, balloons, lidar and radar, Adv. Space Res., 32, 813-818, 2003.

Sassi, F. and Garcia, R. R.: The role of equatorial waves forced by convection in the tropical semi-annual oscillation, J. Atmos. Sci., 54, 1925-1942, 1997.

Sato, K. and Dunkerton, T. J.: Estimates of momentum flux associated with equatorial Kelvin and gravity waves, J. Geophys. Res.102, 26 247-26 261, 1997.

Scaife, A., Butchart, N., Warner, C., and Swinbank, R.: Impact of a spectral gravity wave parameterization on the stratosphere in the met office, J. Atmos. Sci., 59, 1473-1489, 2002.

Tsuda, T., Murayama, Y., Yamamoto, M., Kato, S., and Fukao, S.: Seasonal variation of momentum flux in the mesosphere observed with the MU radar, Geophys. Res. Lett., 17, 725-728, 1990.

Tsuda, T., Tsuda, T., Murayama, Y., Nakamura, T., Vincent, R. A., et al.: Variations of the gravity wave characteristics with height, season and latitude revealed by comparative observations, J. Atmos. Terr. Phys., 56, 555-568, 1994

Vincent, R. A. and Alexander, M. J.: Gravity waves in the tropical lower stratosphere: An observational study of seasonal and interannual variability, J. Geophys.Res., 105, 17 971-17 982, 2000.

Whiteway, J. A. and Carswell, A. I.: Rayleigh lidar observations of thermal structure and gravity wave activity in the high Arctic during a stratospheric warming, J. Atmos. Sci., 51, 3122-3136, 1994.

Whiteway, J. A. and Carswell, A. I. : Lidar observations of gravity wave activity in the upper-stratosphere over Toronto, J. Geophys Res., 100, 14 113-14 124,1995.

Wilson, R., Chanin, M. L., and Hauchecorne, A.: Gravity waves in the middle atmosphere observed by Rayleigh lidar, 1. Case studies, J. Geophys. Res., 96, 5153-5165, 1991a.

Wilson, R., Chanin, M. L., and Hauchecorne, A.: Gravity waves in the middle atmosphere observed by Rayleigh lidar 2. Climatology, J. Geophys. Res., 96, 5153-5165, 1991b. 